JELTL (Journal of English Language Teaching and Linguistics) e-ISSN: 2502-6062, p-ISSN: 2503-1848

2019, Vol. 4(3)

www.jeltl.org

\title{
Measuring the Effect of Parents' Socio-economic Status and Early Literacy Experience on Moroccan Students' Reading Comprehension Development: An Illustration from PIRLS 2016
}

\author{
Neirouz Nadori \\ Chouaib Doukkali University, El Jadida, Morroco \\ e-mail:nadori_neirouz@hotmail.com
}

\begin{abstract}
Because students' reading development is a subject to many influences, home-based factors constitute important components in this process. Parents socio-economic status (parents' occupation and educational level) as well as early literacy experience before school are strongly linked to students' reading comprehension achievement. However, less is known about home-based effects on Moroccan students' reading comprehension development. This research is concerned with investigating the relations between early literacy experience before school, parents' occupation and educational level and reading comprehension development. This study is framed within developmental systems framework. This perspective states that influences on reading achievement do not exist in isolation and that we must direct attention towards examining the interactions between the different layers of the systems (psychological and contextual factors) and the learners' developmental outcomes (reading comprehension achievement). The reading comprehension is measured based on two reading purposes; a) reading for literary experience, b) reading to acquire and use information. Data of 7805 grade 4 students participating in PIRLS 2016 (Progress in International Reading Literacy Study) is investigated. A multilevel linear regression analysis is used to model the relationship between parents' SES, early literacy experience and reading comprehension achievement. These home-based factors explain 15\% of variance in reading achievement. Early literacy activities before school and parents' educational level, particularly fathers' education have a substantial impact on reading comprehension
\end{abstract}


Neirouz Nadori

achievement. These findings have important practical implications for encouraging early literacy experience before school and enhancing parents' educational involvement.

Keywords: early literacy activity, PIRLS 2016, reading comprehension development, SES, systems theory

\section{INTRODUCTION}

Reading comprehension is one of the most important skills that connect to individual's development and personal growth. Besides, reading comprehension is a complex process involving the interactions of various cognitive and non-cognitive influences. The most often quoted studies have demonstrated that socioeconomic status (SES, henceforth) is a strong contributor to children's early reading development (Bradley \& Corwyn, 2002; Gottfried et al., 2015; and Kieffer, 2010). In particular, parents' educational level has been documented to be associated with enhanced reading skills and reading habits (Geske \& Ozola, 2008). Additionally, further studies emphasized the potential of family income in equipping young learners with necessary educational resources such books and other study supports necessary for early reading development. On this basis, Bourdieu (1973) theory of cultural capital ascertains that students' outcomes go beyond demonstrated capabilities to lay emphasis on students' ownership of high levels of cultural competences. Bourdieu's cultural capital incorporates home educational (e.g., reading materials, learning facilities) and cultural (e.g., literature and art work) resources that allow students from affluent families to learn the dispositions, values, perceptions, knowledge, and skills necessary to achieve better gains. Once those competences are transmitted, the learner is therefore supplied with the prerequisite tools and strategies to grow as a proficient reader.

Understanding the significance of learners' SES to subsequent reading comprehension is of paramount importance because students from low-SES backgrounds may be put at increased risk of reading failure (Kieffer \& Lesaux, 2012). These reading difficulties are likely to pursue then throughout their academic course (Stanovich, 1986). Moreover, most studies investigating the relation between early reading activities and reading comprehension development have revealed that early reading experiences positively influence the development of reading abilities (Cunningham \& Stanovich, 1997; Mol \& Bus, 2011; Bergen et al., 2017).

\section{THEORETICAL FRAMEWORK}

Several theorists have investigated skill development in an attempt to explain and understand how it is created and enhanced. The current study is situated within systems theory which places an emphasis on the interaction between individual and contextual factors contributing to reading development and knowledge construction. Systems theory researchers have considered skill development as processes evolving through time that is inextricably embedded in manifold interconnected contextual patterns (Bronfenbrenner, 
1986; Bronfenbrenner, 1979; Gottlieb, 1991; Lerner \& Overton, 2008; Scarr \& Eisenberg, 1993).

Consistent with the purpose of the present study, we have adopted Bronfenbrenner Bioecological system model derived from systems view of human development to investigate how various individual and contextual factors are associated with variation in students' reading comprehension development (Bronfenbrenner \& Morris, 2007). Bronfenbrenner's bioecological system model therefore provides a good framework fit with a view of reading achievement as holistic and developmental in nature. With this regard, this frame views educational outcomes (reading comprehension achievement) as dynamic processes evolving over time and associated with previous experiences as well as predicting future ones (Bronfenbrenner \& Morris, 2007). Another core principle of this approach holds upon the assumption that multivariate contextual environments in which the students are embedded enhance or thwart reading comprehension achievement. For this purpose, Bronfenbrenner differentiated "constructive" from "destructive" environments in terms of their developmental significance (Bronfenbrenner, 1979). Constructive environment involves learners being embedded in the system and events that promote a sense of safety, contribute to skill development and enhancement of achievement. Destructive environment, conversely, compromises safety, engagement, and positive performance.

Under this framework, development occurs within multiple, distinct levels of organization, interacting reciprocally with each other and involves both continuity and change (Bronfenbrenner, 1986 and Lerner \& Overton, 2008). On this basis, parents' SES and their interaction with their children are regarded as proximal influences of students' reading comprehension development.

\section{LITERATURE REVIEW}

\subsection{SES of parents and reading comprehension development}

Socioeconomic status of parents (SES) is probably one of the most influential contextual variables in education research (Sirin, 2005). It encompasses aspects of the individual's, family, or household's relative position in the social hierarchy and is directly concerned with the resources in the home (Hattie, 2009 and Sirin, 2005). Such resources refer to parental income, parental education, and parental occupation as three major indicators of SES (Bradley \& Corwyn, 2002). There is an increasing body of research examining the associations of SES with reading ability (Bergen et al., 2017 and Liu, Georgiou, \& Manolitsis, 2018). Parents from high SES levels have good education and occupation and are therefore better equipped to provide appropriate guidance and financial support to their children's education. They make sure that their children are acquainted with necessary reading-related experiences and engage them in joint reading activities. Parents from low socioeconomic status lack such support, thus children from poor homes are less likely to have support from their parents (Yelkpieri, 2015). In the same vein, Geske \& Ozola (2008) examined the major factors accountable for the low level of students reading among Latvia $4^{\text {th }}$ grade. A group of 3019 pupils used for PIRLS 2001 was subject of investigation. Results revealed that parents' education, which was measured by the number of books at home, was strongly correlated with achievement in reading. Students with higher educated parents were better equipped to use many study aids to assist them in reading. 


\section{Neirouz Nadori}

The same view was held by Welsh et al. (2010) on a study conducted on parents with higher academic background demonstrated that intellectually stimulating parents were more proactive and involved in their children's academic related activities. Such parents participated in various schooling activities mainly, attendance to parents and teachers' meetings and volunteering in school related activities. Through their involvement, parents conveyed the message that school was important and provided their children with positive emotional experiences in relation to school (Engin-Demir, 2009 and Williams \& Rask, 2003).

In addition, Hafiane et al. (2015) carried out a multilevel study in Fez-boulmane region in Morocco on a larger sample of 431 students randomly selected from 9 urban public junior high schools. Hafiane et al. (2015) used Bronfenbrenner Ecological model to examine the relation between individual, home, and school factors and students at risk of failure. They reported that some family related aspect mainly, parents' educational level as well as the students' views about relationships with parents and learning environments at home was predictive of school failure. Findings also revealed that school factors had no effect on the rate of school failure.

However, Johnson (2000) was not in line with previously held assumptions. He claimed that parents' education did not predict achievement in reading comprehension. He found no effect of parental education on the National Assessment of Educational Progress (NAEP) tests. Rather findings revealed that teachers' qualities were better predictors of reading achievement. More than that, Kirsch et al. (2002) ascertained that parents' engagement level in reading activities with their children had more powerful influence on their children reading achievement regardless their educational or occupational level.

\subsection{Early literacy activity and reading comprehension development}

There is a broadly held assumption that early reading experiences before school enhance later reading comprehension gains (Mol \& Bus, 2011 and Hart \& Risley, 2003). Longitudinal research conducted by Hart \& Risley (2003) suggested that differences in vocabulary acquisition appeared at an early age and were predictive of later reading comprehension development. Therefore, early reading experiences could have implications for reading development throughout one's lifespan (Allington, 2001). If these skills are not learned at an early stage, they are unlikely to be learned at all. This phenomenon has been referred to as the 'Matthew Effect', and is first applied to reading development by (Stanovich, 1986). Stanovich (1986) summarized existing research and found that children who had been exposed to print materials at an early age tended to have larger vocabulary repertoire, displayed more motivation to approach a reading activity and were therefore more likely to achieve better reading comprehension gains. So, students' pre-reading activities affected their pre-reading competences and future reading development (Myrberg \& Rosén, 2009). Similarly, Lau, Li, \& Rao (2011) surveyed parents' perceptions of their involvement at home and at school. They analyzed parental engagement at home and at school effects on reading achievement at kindergarten and entering primary school level. Results revealed that language and cognitive home-related experiences were positively associated to reading development. 
Pursuing the same line of research, Mol \& Bus (2011) carried out a meta-analysis to explore the degree of correlation between early print exposure and the development of reading component across time. The scholars synthesized 99 studies $(\mathrm{N}=7,669)$ that examined leisure time reading at different periods of students' academic trajectories: a) preschoolers and kindergarten, b) children attending grades $1-12$, and c) college and university students. Strong associations were found for all measures of reading comprehension and technical reading and spelling. The more exposure to print materials students demonstrated the more proficient in comprehension and technical reading and spelling they became and vice versa. Through their development, students improved their reading comprehension and technical reading and spelling more with each year of education. In other words, the research synthesis reported that early exposure to print accounted for 12 $\%$ of the variance in oral language skill, in primary school $13 \%$, in middle school $19 \%$, in high school $30 \%$, and in college and university $34 \%$. Overall, print exposure did not only impact reading comprehension development, it was associated with general achievement as well.

Similarly, Jeong (2012) analyzed data of early Child longitudinal Study to examine the longitudinal impact pre-school literacy- based activities at home on children's reading scores from kindergarten to grade 5. He found that parental engagement and reading activity at home were linked to children reading achievement test scores at kindergarten, along with changes in scores between each time point. Students' independent reading appeared to be significantly associated with reading development. Hence, both parental involvement and independent reading turned out to benefit students' self-regulatory strategies, interpersonal skills, and reading comprehension growth.

To the best of our knowledge, studies investigating the effects of noncognitive/contextual influences on students' reading comprehension outcomes in the Moroccan context are scare, particularly studies using large scale data. Based on this reasoning, the purpose of the current study is to investigate the extent to which parents' socioeconomic status (parents' educational and occupational level) and early literacy activities before school predict reading comprehension development of Moroccan fourth graders and endeavors to answer three main research questions:

1- To what extent does parents' SES predict reading comprehension development of Moroccan students in grade four?

2- To what extent do early literacy activities predict reading comprehension development of Moroccan students in grade four?

3- How much variance is explained by the combined effects of parents' SES and early literacy activities?

\section{RESEARCH METHODS}

In support of the power of the direct effect that parents' SES and students' preschool literacy experiences has on later reading comprehension development, this investigation seeks to probe the predictive effect of parents' SES and early reading activities on Moroccan fourth graders' reading comprehension achievement. SES dimensions are built upon parents' education and occupation (fathers, mothers or caregivers). The early literacy activities are addressed through the frequency of students' exposure to reading materials and activities 


\section{Neirouz Nadori}

outside school. To this end, the study followed an exploratory research design using context questionnaire and reading comprehension achievement test as data collection instruments. The core principal behind this focus is the assumption that the selected variables might explain to a great extent variation in reading comprehension achievement and that they are malleable and amenable to policy interventions.

\subsection{Sample}

The sample was derived from PIRLS 2016 Morocco study in grade four. It utilized a two-stage stratified random sample design, with a sample of schools drawn as a first stage and intact classes of students selected from each of the sampled schools as a second stage. The use of probability sampling is warranted by the strengths it offers. It allows for both comparability and generalizability from the sample to the target population (martin, Mullis \& Hooper, 2017). PIRLS included three level stratified sampling: students' level, home level and school level. The current study analyses factors at the home level. Over a population of 602,798 students and their parents or guardians, PIRLS conducted a learning to read survey. It has also selected a number of 17,390 schools, 284 public and private schools and 7,805 students based on several coverage and exclusion criteria. The school level exclusion criteria selected are as follow: 1- schools which are inaccessible due to their geographically remote location, 2- schools that are very small in size and include fewer students in the target grade, and 3- schools providing a grade arrangement or curriculum not covered by mainstream educational system. At the student- level exclusion, students with functional or intellectual disabilities as well as students who are unwilling to read or speak the language of the test weren't involved in the study.

\subsection{Measures}

\subsubsection{Reading comprehension test}

The IEA's PIRLS 2016 reading comprehension test was constructed to assess the $4^{\text {th }}$ graders reading comprehension. The test combined 10 passages and questions including a large variety of text types on classroom experiences. Purposes for reading and processes of comprehension constituted the basics framework for the PIRLS written assessment of reading comprehension. The PIRLS assessment covered two inclusive purposes for reading that related to reading experiences inside and outside the classroom: 1- reading for literary experience, 2- reading to acquire and use information. Four types of comprehension processes were dealt with in PIRLS: 1- focus on and retrieve explicitly stated information, 2make straightforward inferences, 3- interpret and integrate ideas and information, and 4examine and evaluate content, language, and textual elements. The four processes were assessed within each purpose of reading. This analysis incorporates the two purposes of reading comprehension. To decrease the effect of fatigue caused by the completion of long tests, PIRLS had resort to a Balanced Incomplete Block (BIB) design (Mullis, Kennedy, Martin, \& Sainsbury, 2007). A multiple imputation technique was utilized to come up with five sets of plausible values of reading scores for the whole sample. To increase the reliability of the test, an Item Response Theory (IRT) was applied to combine the scale of 
students' responses in the test. Additionally, reading achievement scores were IRT scale scores with an international mean of 500 and a standard deviation of 100 .

\subsubsection{Questionnaire}

A context questionnaire was completed by students' parents or guardians. The questionnaire incorporated series of items about preparations for primary schooling, readingbased activities in the home prior to school entrance, such as reading books and singing songs. Parents also provided information concerning their educational and occupational levels. Early parental literacy involvement was captured by parents' involvement in literacy activities with children before primary grades. It examined the degree to which a parent or a caregiver shared various reading activities with his/her child. Respondents were asked the following questions in the parent/primary caregiver questionnaire: "Before your child began the first grade, how often did you or someone else in your family do the following activities with him or her?" Seven of the following activities dealt with language and literacy activities at home: "read books, tell stories, sing songs, play with alphabet toys (for example, blocks with letters of the alphabet), play word games, write letters or words and read aloud signs and labels". Answer categories are often, sometimes and never or almost never.

SES measures classified the educational and occupational level of the father (or stepfather/male guardian) and mother (stepmother/female guardian). Both questions were asked in the home questionnaire. For the educational level, parents were asked to identify, from a number of options, their level of education. The question on occupation was dealt with by asking parents to identify, from a set of options, the type of work that constituted their main occupation. Both parents' education and occupation have been analyzed as continuous variables.

\subsection{Analysis}

The present analysis made use of the IDB analyzer to extract and analyze the data. A multiple linear regression coefficient analysis was adopted to conduct the following analysis. To resolve the problem of missing values that is frequent in large scale studies such PIRLS, a mean substitution mode is utilized. The mean substitution technique allows for the use of cases measuring only continuous variables. It is also noteworthy that the dependent variable (reading comprehension achievement) is used as a plausible value variable.

\section{FINDINGS}

This study was undertaken to gain a better understanding whether and on which dimensions of SES are more effective in enhancing students' reading comprehension achievement. Besides, this study tested the extent to which early literacy activities before school predict/explain the development of reading comprehension achievement. To meet this purpose, a linear regression coefficient was conducted and measured the predictive effects of all the variables in one statistical model. Results are displayed in the following table. 


\begin{tabular}{|c|c|c|c|c|c|c|c|}
\hline \multirow[b]{2}{*}{$\mathrm{t}$} & \multirow[b]{3}{*}{ Variable } & \multirow{2}{*}{ Regression } & \multirow{2}{*}{$\begin{array}{l}\text { Regression } \\
\text { Coefficient }\end{array}$} & \multirow{2}{*}{$\begin{array}{l}\text { Regression } \\
\text { Coefficient }\end{array}$} & \multirow{2}{*}{ Stndrdzd. } & \multirow{2}{*}{$\begin{array}{l}\text { Stndrdzd. } \\
\text { Coefficient }\end{array}$} & \multirow{2}{*}{$\begin{array}{l}\text { Stndrdzd. } \\
\text { Coefficien }\end{array}$} \\
\hline & & & & & & & \\
\hline IDCNTRY & & Coefficient & (s.e.) & (t-value) & Coefficient & (s.e.) & (t-value) \\
\hline \multirow[t]{6}{*}{ Morocco } & (CONSTANT) & 268,34 & 15,21 & 17,64 & & & \\
\hline & ASBH18A & 7,86 & 2,18 & 3,61 &, 15 & .04 & 3,63 \\
\hline & ASBH18B & 6,15 & 2,48 & 2,48 &, 12 &, 05 & 2,53 \\
\hline & ASBH2OA & 3,27 & 1,17 & 2,80 &, 10 &, 04 & 2,79 \\
\hline & ASBH2OB & $-1,27$ & .84 & $-1,52$ &,- 05 &, 03 & $-1,53$ \\
\hline & ASBHELA & 6,71 & 1,85 & 3,62 &, 17 & .05 & 3,50 \\
\hline \multirow[t]{6}{*}{ Table Average } & (CONSTANT) & 268,34 & 15,21 & 17,64 & & & . \\
\hline & ASBH18A & 7,86 & 2,18 & 3,61 &, 15 &, 04 & 3,63 \\
\hline & ASBH18B & 6,15 & 2,48 & 2,48 &, 12 & .05 & 2,53 \\
\hline & ASBH2OA & 3,27 & 1,17 & 2,80 &, 10 & .04 & 2,79 \\
\hline & ASBH2OB & $-1,27$ &, 84 & $-1,52$ &,- 05 &, 03 & $-1,53$ \\
\hline & ASBHELA & 6,71 & 1,85 & 3,62 &, 17 & .05 & 3,50 \\
\hline
\end{tabular}

\subsection{Research question 1: The effects of parents' SES on reading comprehension development}

No statistically significant linear dependence of the mean of mother's occupation on reading comprehension achievement was detected. The T-value of mother's occupation is 1.27 which is smaller than the t-value 1.96 (using a standard normal distribution to determine the critical value for the t-statistics), suggesting no statistically significant relation between the two variables. Parents' educational level (father and mother) as well as father's occupation are statistically significant and positive predictors of reading comprehension achievement. Among all the SES components, the father's educational level has the greatest positive effect on students' reading comprehension achievement with a regression coefficient of 7.86 and a t-value of 3.61 (which is bigger than 1.96) followed by mother's educational status (6.15) and fathers' occupation (2.48).

\subsection{Research question 2: The effects of early literacy activities on reading comprehension development}

The regression coefficient of early literacy activities before elementary school is positive and linearly correlated with reading comprehension achievement with a coefficient of 8.71 and $\mathrm{T}$ value of 3.62. It is important to mention that this variable predicted the 
development of reading comprehension achievement more than parents' occupation. This result suggested that the more parents are involved in early literacy activities the more the reading comprehension achievement of their children improves regardless of their occupation level. Using more technical terms, with every one unit increase in early literacy activities variable, the reading comprehension scores will tend to increase by 8.71 points after controlling for the other variables. The same principle is applicable to the remaining SES constructs.

To summarize the results from this regression model, it was found that SES components (except for mother's occupation variable) were statistically significant and positive predictors of reading comprehension achievement. More precisely, early literacy activities followed by the fathers' educational level were most likely to promote Moroccan fourth graders reading comprehension achievement.

\subsection{The degree of variance explained by the combined effects of SES of parents and early literacy activities}

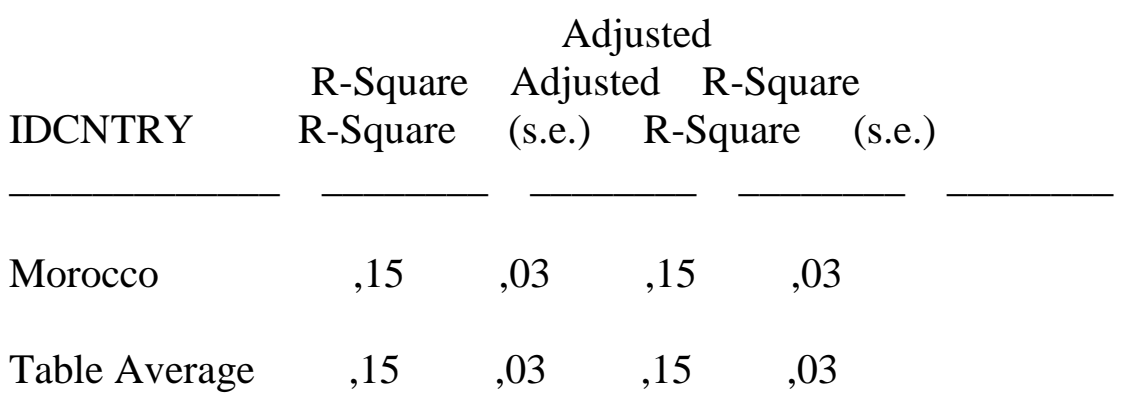

This figure examines the combined effects of early reading activities and SES of parents. The results of the R-Square model revealed that these contextual influences explained 15\% of variance in the reading comprehension scores.

\section{DISCUSSION}

The present study examined whether and which dimensions of SES are related to reading comprehension development and the extent to which parents' involvement in early literacy activities affects reading comprehension gains. Interpretation of key results is provided followed by a discussion of implications for practice stemming from these results.

Overall, this study revealed that Parents' socioeconomic status, except for the mother's occupation was found to have a positive and significant effect on reading comprehension achievement. Parents' involvement in early literacy activities before school and father's educational level contributed to a great extent to the development of reading comprehension achievement. The connections between family background and reading achievement are well understood. In general, more highly educated parents may decide to invest more of their time and energy into educating their children or they may choose to guide their daily interactions with their children in ways that help them succeed at school. Besides, literate parents generally hold positive attitudes towards reading, spend more time reading, and may possess a large variety of books and other educational resources at home. In doing so, parents can 


\section{Neirouz Nadori}

transmit their positive attitudes and their cultural capital to their children which in turn may be conductive to better reading gains (Bourdieu, 1973). Another possible explanation derives from the fact that children who have rich early literacy experiences tend to enroll school with a large vocabulary repertoire and basic reading-related strategies compared to their peers who are not exposed to such activities.

In agreement with the findings of the current analysis, a growing body of literature has established the link between students' SES and early literacy activities and increased reading achievement (Geske \& Ozola, 2008). The researchers investigated the correlation between parents' educational level and students' reading comprehension achievement. They elucidated that parents' education was strongly related to achievement in reading comprehension. Children with higher educated parents were better equipped to make use of various study aids to assist them in reading and to create a congenial atmosphere at home that promoted their learning (Yelkpieri, 2015).

Similarly, Lau et al. (2011) revealed that language and cognitive home-based activities were positively related to reading comprehension development. In fact, intellectually stimulating parents are generally more proactive and more involved in their children reading activities. Through their involvement they not only transfer their positive attitudes towards reading, they convey the message that reading is fundamental for future academic and career success as well.

Following the same line of research, Mol \& Bus (2011) examined the degree of correlation between early print exposure and the development of reading comprehension components across time. They found significant relations between all measures of reading comprehension and technical reading and spelling. Additionally, they postulated that preschool and kindergarten print exposure explained $12 \%$ of variance in later reading comprehension achievement. Bergen et al. (2017) findings were also aligned with the findings of the present analysis. In effect, the authors examined the associations between home literacy environment and children's reading ability and assumed that home literacy reading activities correlated significantly with children's reading ability development. Based on this reasoning, we can assume that the educational opportunities available at home have a substantial influence in explaining disparities in terms of reading among students coming from affluent and less advantaged families.

System theory is another source of support for the findings of the present analysis. Of particular interest in this respect is Bronfenbrenner \& Morris (2007) bioecological model. According to this framework, the microsystem in which the individual develops along with the processes in which he/she engages can be determinant in shaping learners' reading trajectories. The microsystem involves interactions between the learners and their parents. Those interactions are influenced by parents' social and economical characteristics, values, and beliefs. The environments where the learners spend a considerable amount of time can be either constructive or destructive and therefore result to differing reading behaviors and attainments. Overall, findings of our study coupled with empirical studies confirm the assumption that reading development do not occur in isolation, but rather within multiple nested contexts and though dynamic interactions involving various players. 


\section{CONCLUSION AND IMPLICATIONS}

This study aims at assessing the extent to which SES of parents as well as early reading literacy activities influence students' reading comprehension development. Specifically, the study focused on how parents' education and occupation predict/explain reading comprehension scores and the extent to which early reading activities determine students' later reading comprehension development. The theoretical and conceptual framework emphasized the strong and straightforward relationships existing between the students and their contextual environment in explaining variation in reading comprehension gains. Results of our analysis provide a strong support to the association between early reading literacy activities, SES of parents (parents' educational level and occupation) and reading comprehension achievement of Moroccan fourth graders. Early reading literacy activities were found to be highly associated with reading comprehension achievement followed by fathers' and mothers' educational level.

Based on the findings and conclusions drawn from the study, a set of recommendations are made. The findings would encourage more parental involvement especially at early stages of their children schooling. Parents greatly contribute to their children reading skill enhancement through helping them prepare for the demands of formal schooling and learning to read. Accordingly, the home-related environments are crucial settings for the acquisition of early literacy experiences such as engaging in joint literacy activities with family members, being initiated to basic reading skills, and benefiting from teaching strategies that family members use when engaging in literacy activities.

Similarly, teachers should not presume that all students enroll school with similar levels of reading related abilities and behaviors. Lack of basic reading skills among students coming from disadvantaged families is ubiquitous as they may have insufficient books or joint literacy experiences as their counterparts. Students from low socioeconomic families and whose both parents are illiterate should be identified by school. The school can eventually provide remedial programs to enable those children overcome reading -related difficulties that are likely to follow them throughout their school years (Cunningham \& Stanovich, 1997; Mol \& Bus, 2011; Stanovich, 1986).

This study has also practical important implications for policy interventions. Policy makers should intensify non-formal education which aims at providing adults with literacy and numeracy knowledge. This will help parents become more engaged in their children early literacy experiences. The government should also expand and make preschool programs free to cover all categories of children.

\section{REFERENCES}

Allington, R. (2001). What Really Matters for Struggling Read-Ers: Designing ResearchBased Programs. The Reading Teacher, 66(7), 520-530.

Bergen, E., Zuijen, T., Bishop, D., \& Jong, P. F. (2017). Why are Home Literacy

Environment and Children's Reading Skills Associated? What Parental Skills Reveal.

Reading Research Quarterly, 52(2), 147-160.

Bourdieu, P. (1973). Cultural Reproduction and Social Reproduction. London: Tavistock. Bradley, R. H., \& Corwyn, R. F. (2002). Socioeconomic Status and Child Development. 
Neirouz Nadori

Annual Review of Psychology, 53(1), 371-399.

Bronfenbrenner, \& Morris, P. A. (2007). The Bioecological Model of Human Development. Theoretical Models of Human Development, 1.

Bronfenbrenner, U. (1979). Contexts of Child Rearing: Problems and Prospects. American

Psychologist, 34(10).

Bronfenbrenner, U. (1986). Ecology of the Family as a Context for Human Development:

Research Perspectives. Developmental Psychology, 22(6).

Cunningham, A. E., \& Stanovich, K. E. (1997). Early Reading Acquisition and its Relation

to Reading Experience and Ability 10 Years Later. Developmental Psychology, 33(6).

Engin-Demir, C. (2009). Factors Influencing the Academic Achievement of the Turkish

Urban Poor. International Journal of Educational Development, 29(1), 17-29.

Geske, A., \& Ozola, A. (2008). Factors Influencing Reading Literacy at the Primary School

Level. Problems of Education in the 21st Century, 6.

Gottfried, A. W., Schlackman, J., Gottfried, A. E., \& Boutin-Martinez, A. S. (2015). Parental

Provision of Early Literacy Environment as Related to Reading and Educational

Outcomes Across the Academic Lifespan. Parenting, 15(1), 24-38.

Gottlieb, G. (1991). Experiential Canalization of Behavioral Development: Theory.

Developmental Psychology, 27(1).

Hafiane, S., Elachqar, A., Elaissaoui, K., \& Tahraoui, A. (2015). Major Factors that Influence School Failure in the Northern Region of Morocco. Procedia - Social and Behavioral Sciences, 197, 2164-2173.

Hart, B., \& Risley, T. R. (2003). The Early Catastrophe: The 30 Million Word Gap by Age

3. American Educator, 27(1), 4-9.

Hattie, J. (2009). The Contributions from Teaching Approaches. Visible Learning: A

Synthesis of Over, 800, 161-199.

Jeong, H. (2012). A Comparison of the Influence of Electronic Books and Paper Books on Reading Comprehension, Eye Fatigue, and Perception. The Electronic Library, 30(3), 390-408.

Johnson, W. A. (2000). Toward a Sociology of Reading in Classical Antiquity. American Journal of Psychology, 121(4), 593-627.

Kieffer, M. J. (2010). Socioeconomic Status, English Proficiency, and Late-Emerging

Reading Difficulties. Educational Researcher, 39(6), 484-486.

Kieffer, M. J., \& Lesaux, N. K. (2012). Direct and Indirect Roles of Morphological

Awareness in the English Reading Comprehension of Native English, Spanish, Filipino, and Vietnamese Speakers. Language Learning, 62(4), 1170-1204.

Kirsch, I., De Jong, J., Lafontaine, D., McQueen, J., Mendelovits, J., \& Monseur, C. (2002). Reading for Change. Paris: Oese.

Lau, E. Y., Li, H., \& Rao, N. (2011). Parental Involvement and Children's Readiness for School in China. Educational Research, 53(1), 95-113.

Lerner, R. M., \& Overton, W. F. (2008). Exemplifying the Integrations of the Relational Developmental System: Synthesizing Theory, Research, and Application to Promote Positive Development and Social Justice. Journal of Adolescent Research, 23(3), 245255. 
Measuring the Effect of Parents' Socio-economic Status and Early Literacy Experience

Liu, C., Georgiou, G. K., \& Manolitsis, G. (2018). Modeling the Relationships of Parents' Expectations, Family's SES, and Home Literacy Environment with Emergent Literacy Skills and Word Reading in Chinese. Early Childhood Research Quarterly, 43, 1-10.

Mol, S. E., \& Bus, A. G. (2011). To Read or not to Read: a Meta-Analysis of Print Exposure from Infancy to Early Adulthood. Psychological Bulletin, 137(2).

Mullis, I. V. S., Kennedy, A. M., Martin, M. O., \& Sainsbury, M. (2007). Assessment Framework and Specifications. Chestnut Hill, MA: TIMSS \& PIRLS International Study Center, Boston College.

Myrberg, E., \& Rosén, M. (2009). Direct and Indirect Effects of Parents' Education on Reading Achievement among Third Graders in Sweden. British Journal of Educational Psychology, 79(4), 695-711.

Scarr, S., \& Eisenberg, M. (1993). Child Care Research: Issues, Perspectives, and Results. Annual Review of Psychology, 44(1), 613-644.

Sirin, S. R. (2005). Socioeconomic Status and Academic Achievement: A Meta-Analytic Review of Research. Review of Educational Research, 75(3), 417-453.

Stanovich, K. E. (1986). Matthew Effects in Reading: Some Consequences of Individual Differences in the Acquisition of Literacy. Reading Research Quarterly, 22, 360-407.

Welsh, J. A., Nix, R. L., Blair, C., Bierman, K. L., \& Nelson, K. E. (2010). The Development of Cognitive Skills and Gains in Academic School Readiness for Children from Low-Income Families. Journal of Educational Psychology, 102(1).

Williams, M., \& Rask, H. (2003). Literacy through Play: How Families with able Children Support their Literacy Development. Early Child Development and Care, 173(5), 527533.

Yelkpieri, D. (2015). Socioeconomic Status of Parents and Its Effects on Students' Achievement in the Awutu Senya and Effutu Educational Directorates in the Central Region of Ghana. University of Leicester. 